\title{
The Role of Group Size and Correlated Project Outcomes in Group Lending
}

\author{
Marina Markheim \\ Department of Economics, University of Regensburg, Regensburg, Germany \\ Email: marina.markheim@ur.de
}

How to cite this paper: Markheim, M. (2017) The Role of Group Size and Correlated Project Outcomes in Group Lending. Theoretical Economics Letters, 7, 11891200.

https://doi.org/10.4236/tel.2017.75080

Received: June 1, 2017

Accepted: July 18, 2017

Published: July 21, 2017

Copyright $\odot 2017$ by author and Scientific Research Publishing Inc. This work is licensed under the Creative Commons Attribution International License (CC BY 4.0).

http://creativecommons.org/licenses/by/4.0/

\begin{abstract}
This paper analyzes contract efficiency with regard to correlated project realization and the size of the borrowers in group lending. Firstly, I show that under the standard assumption of independent project payoffs, the expected group cost of default decreases with group size. Secondly, I show that small groups can also optimize group efficiency if individual payoffs and credit risks are correlated. The results outline that social cost minimization occurs due to a common interest in forming optimal borrower groups between lenders and borrowers.
\end{abstract}

\section{Keywords}

Microfinance, Group Lending, Strategic Default, Group Size, Correlated Credit Risk

\section{Introduction}

The United Nations recognizes the importance of microfinance as a major tool for achieving Millennium Development Goals. One of these goals is helping the poor and needy to break out of poverty, thereby promoting economic growth. The microfinance sector provides different financial services like microsaving, microinsurances, remittances, microloans, and other basic financial services to the underserved or vulnerable parts of society. The development of microcredit gives the poor access to capital. Microloans facilitate provisions of low value credits and the most typical characteristics are: (a) the micro-borrowers are from low-income groups and are excluded from the financial sector; (b) the microfinance-clients are predominantly female. (c) The loan values are small amounts. (d) The loans are borrowed to generate income activities or for other basic needs. (e) The credit term of the loan is short e.g., small weekly repayments. (f) The low-income customers have insufficient or even no physical collateral and no 
credit history.

Currently, microfinance institutions (MFIs) use diverse models to provide micro loans. Most of these MFI models are based on group lending and known as the Joint Liability Group (JLG). The size of the groups can vary from five borrowers for the Grameen Model, to 15 - 30 for Village Banking and Self Help Groups (e.g., FINCA group involves 30 women). With the JLG method, the borrowers build groups voluntarily and guarantee each other's loans. If any member of the group runs into repayment problems, the other individuals are responsible and need to repay that loan. For JLG practices, the rate of recovery is high, for instance the Grammen Bank reports a level of $\$ 98.76 \$$ percent [1].

Because the group members come from the same neighborhood, they are well informed about the ability and willingness of fellow members to repay their loans. Thus, a JLG can replace the lack of physical collateral and helps to reduce the problems of asymmetrical information (e.g., [2] [3] [4]). Conversely, selfselected group members, who have similar characteristics (e.g., same village, same gender, same type of business, same level of education etc.) can generate a negative impact on risk-sharing within the group. Consequently, the risk sharing becomes increasingly difficult for large groups due to the snowball effect of defaulting on loans (e.g., [5]).

There is extensive literature showing how group lending contracts can improve efficiency in contexts where borrowers share some social asset. However, the literature almost always engages with group size of two borrowers, and ignores correlated risk. Some of the first formal models, to discuss group size, are provided by [6], [7] and [8]. These papers discussed how when group size is placed in different context, large group size can improve efficiency. Baland et al., (2013) [9] explored interaction between group size, wealth and projects characteristics. They showed, that a small group size can increase efficiency when access to credit is limited by strategic default and found that group lending with two borrowers in never optimal for small loans but the benefit is not monotonic. For example, [10] assumed that project are statistically independent and shown in the adverse selection, the ex ante moral hazard and the ex post moral hazard settings, how the effect of group size varies with social capital. He founded that some social asset is essential for endogenous group size to have any effect.

Yet, the research does not present a fully settled view on group size. I explore the interaction between group size and correlated project realizations in the setting of strategic default, in contrast to earlier theoretical literature (e.g., [11] [12] [13] [14]). This paper contributes to the literature on group size in micro lending in two ways, namely the structure and performance of optimal group credit contracts group size and the degree of correlated risk varies this document seeks to generalize along both group-size and correlated risk dimensions in the strategic default context. My results show that by distinguishing group size variation and correlated project realization in the group building processes yields more accurate theories of micro credit and, in turn, improves our understanding of group lending. 
Many theoretical researches on group lending assume that the project realizations are statistically independent, thus a part of the risk can be diversified. As shown in this paper (see Section 3) a bigger group is better in the risk sharing and minimizing of deadweight losses. By introducing the statistical linear relationship (see Sections 4 und 5), I find the optimal group size is unique to each group. This paper provides the novel theoretical explanation of a strong relationship between correlated project outcomes and group size while focuses on the limited abilities of risk sharing within the homogeneous group.

The rest of the article is organized as follows. The next section starts with a brief overview of the study of [13], henceforth: "RS" as a benchmark. The RS theory engages with mechanism design, which investigates the impact of JLG on formal and informal contractual arrangements influenced by internal and external frictions. In Sections 3, 4, and 5, I modify the RS-setting, which is based on a group size of more than two borrowers and the correlated project realization. Section 6 shows a numerical example. Finally, I present some concluding remarks and discuss potential implications for future research.

\section{The Basic Model}

The RS model only considers the problem of strategic default. Similar to the RSmodel, I initially analyzed the environment with two borrowers $n=2$. They are homogeneous by risk and endowed each borrower with a risky projects and one unit of labor. Because of the homogeneity assumption, the projects have the same probability of success $0<p<1$, and generate income $h>0$ per borrower. The payoff is a Bernoulli random variable

$$
X \sim \operatorname{Ber}(p)=\left\{\begin{array}{l}
X=1, \text { for } p \\
X=0, \text { for } q .
\end{array}\right.
$$

Thus with the probability $P(X=1)=p$ corresponding to a payoff of $h>0$ and $P(X=0)=1-p \equiv q$ corresponding to a payoff of zero $(h=0)$. Villagers are risk-neutral and have a choice between being an employee or investing in their own business. Said borrowers have no physical capital and the local lenders, MFIs, provide the only way for them to raise money. By deciding to create a business, they can choose to accept either a JLG contract or an individual lending (IL) contract. Borrowers can observe the realization of the project and each other's goals at no cost. I assume that alternative income generating activities creates wealth $u=0$. The borrowers observe the each others' project realizations free of charge.

The MFIs operate on either on a perfectly competitive market so that it cannot charge more than it costs or they are a non-profit organization. The lenders are also risk-neutral and have no information about the borrowers' actions. Thus they can only observe this state by paying an observational cost. To reduce strategic default in this model, the MFIs can impose endogenous non-monetary punishments $C$, which create deadweight losses and market inefficiency (see e.g. [11] [14], p. 62). I assume that the decision maker will behave rationally. The challenge in this setting is to delineate efficient contracts by minimizing the total 
expected cost of default, which is defined for the group lending contract with two borrowers as follows: with $E C_{2} \equiv P\left(X_{1}=0, X_{2}=0\right) C_{2}$ and for the individual lending contract with $E C_{1} \equiv P\left(X_{i}=0\right) C_{1}, \forall i=1,2$.

Definition: $A$ loan contract is efficient and maximizes borrowers utilities if it satisfied this criteria:

- minimizing the expected cost of default (known as deadweight losses) subject to (a) borrowers participation constraints $(P C),(b)$ MFI's break-even constraint (ZPC), and (c) incentive compatibility constraints (ICC).

- If the condition $E C_{2} \leq E C_{1}$ holds, the group-based contract dominates the individual liability loan.

To compute this condition, we compare Equation (6) with Equation (10), which is shown as inequality (11). Assuming borrowers decide on an investment, financed by a group lending contract, then four states of probabilities are possible, as shown in Table 1. If projects are randomly distributed then both borrowers are successful with the probability $p_{2}^{s}$. With the probability $p_{2}^{f}$ both borrowers fail, and with the probabilities $p_{2}^{c}$ the debt payments are protected by joint liability.

I use the information in Table 1 and Equation (1) to determine three contract constraints, which are summarized below

$$
\underbrace{p_{2}^{s}+2 p_{2}^{c}}=\underbrace{\left(1-p_{2}^{f}\right)} \text {. }
$$

For individual lending (IL) the borrowers' expected utility is given by

$$
E U_{1}=E\left(h-R_{1}\right)-E C_{1} .
$$

Thus the borrowers' participation constraint can be rewritten as

$$
P C_{1}: E\left(h_{i}-R_{i}\right)-E C_{1} \geq u \text {. }
$$

By solving the lender break-even constraint the MFI charges the interest rate

$$
Z P C_{1}: R_{1}=\frac{1}{p} \text {. }
$$

Besides both constraints above, the incentive compatibility constraint can be rewritten as

\begin{tabular}{|c|c|c|c|c|}
\hline & & Borrower & & \\
\hline \multirow{4}{*}{ Borrower 1} & & $\begin{array}{l}\text { Success: } h>0 \\
\text { with } P(X=1)\end{array}$ & $\begin{array}{c}\text { Failure: } h=0 \\
\text { with } P(X=0)\end{array}$ & $\Sigma$ \\
\hline & $\begin{array}{l}\text { Success: } \quad h>0 \\
\text { with } P(X=1)\end{array}$ & $p_{2}^{s}=p^{2}$ & $p_{2}^{c}=q p$ & $p$ \\
\hline & $\begin{array}{l}\text { Failure: } h=0 \\
\text { with } P(X=0)\end{array}$ & $p_{2}^{c}=q p$ & $p_{2}^{f}=q^{2}$ & $q$ \\
\hline & $\Sigma$ & $p$ & $q$ & 1 \\
\hline
\end{tabular}

$$
\text { ICC }{ }_{1}: C_{1} \geq C_{1}^{\min } \equiv R_{1}
$$

Table 1. The four possible states of randomly distributed payoffs. 
Therefore, each borrowers' expected cost of default reads as follows in Equation (6)

$$
E C_{1} \equiv q R_{1}=\frac{q}{p}
$$

In the case for group lending with two borrowers is applicable. The borrowers' participation constraint can be rewritten as follows in inequality (7)

$$
P C_{2}: E\left(h_{2}-R_{2}\right)-E C_{2} \geq u \text {. }
$$

By solving the lender break-even constraint and the incentive compatibility constraint the MFI charges the interest rate and the non-monetary punishments $C$ as follow in Equation (8) and inequality (9)

$$
\begin{gathered}
Z P C_{2}: R_{2}=\frac{1}{1-p_{2}^{f}}, \\
I C C_{2}: C_{2} \geq C_{2}^{\min } \equiv 2 R_{2} .
\end{gathered}
$$

In the context of JLG, the expected cost of default for each borrower is given by the following

$$
E C_{2} \equiv q^{2} 2 R_{2}=2 \frac{p_{2}^{f}}{1-p_{2}^{f}}
$$

Then, group-based contracts $E C_{2}$, shown as Equation (10), are compared with individual lending contracts $E C_{1}$, and shown as Equation (6).

Main findings from RS (2010): the group-based contracts are more efficient in comparison to individual-based contracts with regard to reduction of social costs. It does not matter whether the group's commitments, to help each other are formal or informal arrangements. The condition described as inequality (11) holds for the group-based contracts with the size of $n=2$ borrowers

$$
E C_{2}<E C_{1}
$$

These findings hold true as long as the borrowers are fully informed about the other members within the group. If there is internal friction within the group, the lender can create an environment (e.g., public meeting or message game) to achieve the second best or even the first best solution outcome for the borrowers (see e.g. [13]).

\section{Efficiency Lending Contracts with $n \geq 2$ Borrowers}

In the previous section, I consider the group size of two borrowers. To check the robustness of RS results I extend the model from $n=2$ to $n>2$ borrowers, as formulated in Proposition (1). Moreover, I assume, without leaving out anything essential that expected project payoffs $h$ are uncorrelated and large enough to satisfy inequality (12)

$$
E h>E R \Rightarrow n p h>n
$$

and $\forall n>1$ implies $p h>1$. The expected repayment would be $E R_{n}=n$, so the bank breaks even and implies each villager's expected surplus 


$$
E\left(h_{n}-R_{n}\right)=n(p h-1)>0 .
$$

In the case for group lending with more than two borrowers:

$$
\begin{gathered}
P C_{n}: E\left(h_{n}-R_{n}\right)-E C_{n} \geq 0 \\
Z P C_{n}: R_{n}=\frac{1}{1-q^{n}} \\
I C C_{n}: C_{n} \geq C_{n}^{\min } \equiv n R_{n}
\end{gathered}
$$

In the context of JLG, the expected cost of default for each borrower is given by the following Equation (17)

$$
E C_{n} \equiv q^{n} n R_{n}=\frac{n q^{n}}{1-q^{n}} .
$$

Proposition 1 (Efficiency of $J L G$ with $n>2$ ):

If the outcomes of all borrowers's projects are a Bernoulli random variable $X \sim \operatorname{Ber}(p)$ with parameter $p$, expected value $E(X)=p$ and with Variance $\operatorname{Var}(X)=p q$, then Comparing the group lending to individual lending contracts, the JLG always minimizes the social costs of the group for all group sizes larger than one

$$
E C_{n} \equiv \frac{n q^{n}}{1-q^{n}}<\frac{q}{p} \equiv E C_{1}
$$

Prof:

1. If $X_{1}, X_{2}, \cdots, X_{n}$ are discrete random variables with parameter $P\left(X_{i}=0\right)=q_{i}$ then their joint probabilities of default is computed by

$$
P\left(X_{1}=0, X_{2}=0, \cdots, X_{n}=0\right)=P\left(X_{1}=0\right) P\left(X_{2}=0\right) * \cdots * P\left(X_{n}=0\right),
$$

2. then it is equivalent to $q * \cdots * q=q^{n}$.

3. According to

$$
\lim _{n \rightarrow \infty} E_{n}=0 \text { and with } \frac{\partial E C_{n}}{\partial n}<0 .
$$

I prove the robustness of the RS theory and conclude that the larger the group size, the smaller the social costs, which are defined by the expected cost of default as in (17).

It is remarkable within this framework that by increasing $n$, the Second Best equivalent to the First Best solution can be obtained.

\section{The Correlated Project Realization}

The considering that in practice the risk of defaults is correlated, I verify position that:"The existence of correlation would only strengthen the results of this analysis" ([3], p. 353). For Example, [15] analyzes inter-group risk sharing and concludes that the defaults of the self selected group members are correlated and thus illuminates the anti-diversification results. Both statements allow me to assume that the borrowers' project returns are linearly dependent. Through this assumption, I can observe the impact of the correlation on RS-results in the group lending framework. 
Again for simplicity, I start with a group size of two borrowers. Unlike the previous assumption, the payoff of both borrowers is correlated. In this set up with two borrowers, there are four possible probability realizations as expressed in Table 2.

In this Table 2, in the first case with a probability of $p_{2}^{s, \rho}=p^{2}+\tilde{\rho}$, with $\tilde{\rho}=\rho p q \quad$ (obtained from (19) and (20))both borrowers are successful and repay their debt completely. The second and third cases are symmetrical: with a probability of $p_{2}^{c, \rho}=p q-\tilde{\rho}$, both of these (e.g. borrower 1) needs to pay for himself and for borrower 2 and vice versa in case three. As a result of group lending assurance, the creditor will receive the full repayment in all of these cases. The most interesting situation is the probability of $p_{2}^{f, \rho}=q^{2}+\tilde{\rho}$, where both borrowers fail and there is no repayment to the MFI. Note that project outcomes corresponding to a payoff of zero. With the Covariance between two realizations is

$$
\operatorname{Cov}\left(X_{1} X_{2}\right)=P\left(X_{1}=0, X_{2}=0\right)-P\left(X_{1}=0\right) P\left(X_{2}=0\right) .
$$

If $X_{1}$ and $X_{2}$ are statistically independent, then $\operatorname{Cov}\left(X_{1} X_{2}\right)=0$ and if $\operatorname{Cov}\left(X_{1} X_{2}\right) \neq 0$, then $P\left(X_{1}=0, X_{2}=0\right) \neq P\left(X_{1}=0\right) P\left(X_{2}=0\right)$.

To calculate the joint probability of the failure event $p_{2}^{f, \rho}$, I used the linear relationship of the borrower' s project outcomes. The correlation coefficient $\rho$ is described by

$$
\rho=\frac{\operatorname{Cov}\left(X_{1} X_{2}\right)}{\sqrt{\operatorname{Var}\left(X_{1}\right) \operatorname{Var}\left(X_{2}\right)}}
$$

or this formula can be rewritten using Steiner translation theorem as:

$$
\rho=\frac{p_{2}^{f, \rho}-q^{2}}{\sqrt{\operatorname{Var}\left(X_{1}\right) \operatorname{Var}\left(X_{2}\right)}}
$$

The default correlation coefficient $\rho$ between $P\left(X_{1}=0\right)$ and $P\left(X_{2}=0\right)$ has the value $-1 \leq \rho \leq 1$ on the interval.

Table 2 summarizes the probabilities of correlated outcomes in four possible events, with the parameter $\tilde{\rho}=\rho p q, \quad p=p_{2}^{s, \rho}+p_{2}^{c, \rho}$ and $q=p_{2}^{f, \rho}+p_{2}^{c, \rho}$. The sum $\Sigma$ can be rewritten as Equation (21)

$$
\underbrace{p_{2}^{s, \rho}+2 p_{2}^{c, \rho}}=\underbrace{1-p_{2}^{f, \rho}}
$$

\begin{tabular}{|c|c|c|c|c|}
\hline & & Borrower 1 & & \\
\hline \multirow{4}{*}{ Borrower 2} & & $\begin{array}{c}\text { Success: } h>0 \\
\text { with } P(X=1)=p\end{array}$ & $\begin{array}{c}\text { Failure: } h=0 \\
\text { with } P(X=0)=q\end{array}$ & $\Sigma$ \\
\hline & $\begin{array}{c}\text { Success: } h>0 \\
\text { with } P(X=1)=p\end{array}$ & $p_{2}^{s, \rho}=p^{2}+\tilde{\rho}$ & $p_{2}^{c, \rho}=p q-\tilde{\rho}$ & $p$ \\
\hline & $\begin{array}{c}\text { Failure: } h=0 \\
\text { with } P(X=0)=q\end{array}$ & $p_{2}^{c, \rho}=p q-\tilde{\rho}$ & $p_{2}^{f, \rho}=q^{2}+\tilde{\rho}$ & $q$ \\
\hline & $\Sigma$ & $p$ & $q$ & 1 \\
\hline
\end{tabular}

Table 2. The four possible states of realization with correlated project outcomes. 
By applying these results, I calculate expected cost $E C_{2}^{\rho}$ for $n=2$ and compare it to $E C_{1}$ to conclude which contract is still efficient with regard to three constraints: (a) PC, (b) ZPC and (c) ICC as shown below:

$$
\begin{gathered}
P C_{2}^{\rho}: E h_{2}^{\rho}-E R_{2}^{\rho}-E C_{2}^{\rho} \geq 0 ; \\
Z P C_{2}^{\rho}: R_{2}^{\rho}=\frac{1}{1-p_{2}^{f, \rho}} ; \\
I C C_{2}^{\rho}: C_{2}^{\rho} \geq C_{2}^{\rho, \min } \equiv 2 R_{2}^{\rho} .
\end{gathered}
$$

In the context of JLG, the expected cost of default for each borrower is given by the following Equation (25)

$$
E C_{2}^{\rho}=\frac{2 p_{2}^{f, \rho}}{1-p_{2}^{f, \rho}}
$$

The results of Equations (25) and (6) give us Proposition 2, which describes the efficiency contracts in this framework.

Proposition 2 (Efficiency of JLG with correlated project realization):If the project outcomes are correlated, then the IL contract should be compared with the JLG contract. As long as the following condition is satisfied

$$
\rho^{*} \equiv \rho<\frac{p}{1+p}=\frac{1-q}{2-q}
$$

(with $\frac{\partial \rho^{*}}{\partial p}>0$, and $\frac{\partial \rho^{*}}{\partial q}<0$ ), the group based contract always minimizes the social costs of the group size $n=2$.

Prof: The condition of Proposition 2 comes from comparing Equation (6) with Equation (25) and is described as

$$
E C_{2}^{\rho}<E C_{1} .
$$

Condition as inequality (27) is satisfied for $\rho=0$, which is similar to the results in Section 2. In addition, this condition satisfied $\rho>0$ but only when the parameter is smaller than $\rho^{*}$ as defined in (26).

\section{Efficiency Lending Contracts with $\mathrm{n}$ Borrowers}

I delineate a homogeneous JLG of $\mathrm{n}$ members. The project outcomes of borrowers are correlated. The group size of $n>2$ has $n(n-1) / 2$ counterparties, whose defaults are correlated with the correlation coefficient $\rho$ between each pair. Secondly, the failure probability in the group for each borrowers is the same and is denoted by $q$. Thirdly, the size of each credit in the group is one unit of capital. In this framework with $\mathrm{n}$ borrowers, there are $2^{n}$ possible probability events:

$$
P_{i j}=\left(\begin{array}{c}
p_{n}^{s, \rho} \\
p_{n}^{c, \rho} \\
\vdots \\
p_{n}^{c, \rho} \\
p_{n}^{f, \rho}
\end{array}\right)=\left(\begin{array}{c}
P\left\{X_{i}=1 \mid X_{i-1}=1\right\} \\
P\left\{X_{i}=1 \mid X_{i-1}=0\right\} \\
\vdots \\
P\left\{X_{i}=0 \mid X_{i-1}=1\right\} \\
P\left\{X_{i}=0 \mid X_{i-1}=0\right\}
\end{array}\right), \forall i=2, \cdots, n
$$


As a result of JLG, if the expected project payoffs are large enough to satisfy

$$
\left(1-p_{n}^{f, \rho}\right) h>n
$$

and define $C_{n}^{\rho} \geq C_{n}^{\rho, \text { min }} \equiv n R_{n}^{\rho}$ is the total expected number of defaults in the group lending $n R_{n}^{\rho}$ thus $E C_{n}^{\rho}=p_{n}^{f, \rho} n R_{n}^{\rho}$, then the lender will receive the full repayment in all these events except in the last case $p_{n}^{f, \rho}$. This case implies that all borrowers fail, resulting in no repayment to the MFI, and the total number of defaults is $\sum_{1}^{n}\left(X_{i}=0\right)=n$. The joint probability $p_{n}^{f, \rho}$ takes on the value of the interval $0<p_{n}^{f, \rho}<q$. Using this information, I distinguish three extremes: in the case of pairwise independent outcomes, it means that $\operatorname{Cov}\left(X_{i} X_{j}\right)=0$ thus $\rho=0$. Then the corresponding value of the joint probability of total default has the value of $p_{n}^{f, \rho}=q^{n}$. This result is consistent with RS' findings and proposition 1 . In the other extreme of perfect positively correlated defaults, the variance of a homogeneous group is $n^{2} q p$ and the joint probability of the total default corresponds to $p_{n}^{f, \rho}=q$. The third extreme, which implies $p_{n}^{f, \rho}$ has the value of zero. As a result of these extremes the joint probability of defaults has the value $0<p_{n}^{f, \rho} \leq q$ for

$$
\frac{0-q^{n}}{p q} \leq \rho \leq 1 .
$$

This information is useful for creating the linear relationship between expected cost of default and the correlation coefficient as described in Equation (31)

$$
E C_{n}^{\rho}=\frac{n q^{n}}{1-q^{n}}(1-\rho)+\frac{n q}{p} \rho .
$$

Proposition 3 (Efficiency of JLG with correlated project realization and $n$ borrowers): If the project outcomes are correlated, with $\rho$ for all pairs of borrowers $(i \neq j)$, then the IL contract should be compared with a JLG contract. As long as the following condition is satisfied

$$
\rho^{* *} \equiv \rho \leq \frac{\frac{q}{p}-\frac{n q^{n}}{1-q^{n}}}{\frac{n q}{p}-\frac{n q^{n}}{1-q^{n}}}
$$

the group based contract for $n \geq 2$ always minimizes the social costs.

Proof. The condition of Proposition 3 is calculated by comparing the expected costs of defaults between $E C_{n}^{\rho}$ in (31) and $E C_{1}$ in (6), is described by (33)

$$
E C_{n}^{\rho} \leq E C_{1} \text {. }
$$

\section{Numerical Example}

In this section, to provide a better understanding of my findings, I computed the expected cost of default depending on the correlation parameter as provided in Equation (31). In this numerical example I assume that $p=0.5$, then $q=1-p=0.5$. Figure 1 illustrates the results, where the $\mathrm{x}$-axis represents the 


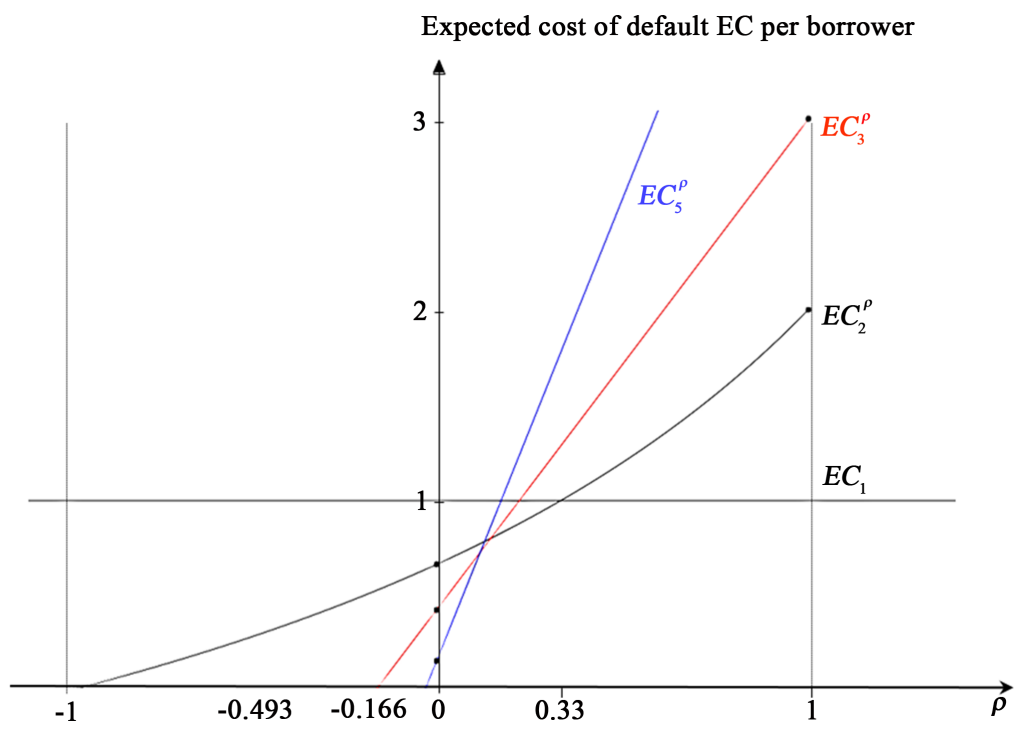

Figure 1. Expected cost of default dependence on $\rho$ and on group size $n$.

correlation coefficient. The y-axis represents the expected cost of default per borrower.

The horizontal curve $E C_{1}$ describes the expected cost for an individual lending contract and the three other curves describe group-based lending contracts. The black curve is calculated for $n=2$ borrowers, the red curve is calculated for $n=3$ borrowers, and the blue curve is calculated for $n=5$ borrowers. This picture illustrates the relationship between a correlation parameter $\rho$ and group size $n$ on the expected cost of default. As before, (33) implies that the group based contract of size $n \in(2 ; N)$ dominates the individual lending until the condition for $\rho_{i j}^{* *}$ if proposition 3 holds. By using Equation (31) as follows for $n=5$ and $p=q=0.5$ follows that

$$
E C_{5}^{\rho}=5 \frac{0.5^{5}}{1-0.5^{5}}(1-\rho)+5 \rho \frac{0.5}{0.5} \text { and } E C_{1}^{\rho}=\frac{0.5}{0.5}=1 .
$$

Compare both Equations for the correlation parameter thus, $E C_{5}<E C_{1}$ for $\rho^{* * *}<0.173$, for the couple $E C_{5}<E C_{3}$ implies $\rho^{* * *}<0.118$ and so forth, I show the impact of the correlation coefficient in an optimal group size context. This example strengthens the importance of the correlated outcomes and endogenous group size in the context of efficient group lending contracts. By summarizing the optimal group size results from this numerical example, I point out the minimized expected cost of default, which is distinguished by group size and depends on correlation $\rho$

$$
E C_{n}^{\rho}=\left\{\begin{array}{l}
n^{*}=5, \text { for } \rho \in[-1.00 ; 0.118) \\
n^{*}=3, \text { for } \rho \in[0.118 ; 0.191) \\
n^{*}=2, \text { for } \rho \in[0.191 ; 0.330) \\
n^{*}=1, \text { for } \rho \in[0.330 ; 1.00] .
\end{array}\right.
$$

These results clearly show why correlation has a significant impact on optimal group size as characterized by minimizing the expected cost of default. 


\section{Conclusions}

In this paper, I characterized a finite optimal group size with positively correlated project outcomes in a strategic default setting. Furthermore, I focus on sensitization of the fundamental question of microcredit risk from the perspective of the optimal lending contract when the group size is endogenous and the risks are correlated. As we have seen, the correlation can be a major obstacle for the development of micro and small business in an Emerging Market.

Again, I add to the existing literature on efficient group lending to consider the impact of correlation and of group size. The core of this paper shows that efficient contracts are dependent on appropriate group size in respect to statistical interdependence among project outcomes and credit risks as shown in Figure 1. I must emphasize that this research does not aim to solve the problem of strategic default and group-building process. Since the economy is complex, I do not know how much this new point of view will affect the future economic studies and the field experiments. Therefore future research should provide more information and evidence on this topic. I hope that this short discussion underlines the need to investigate the influence of inter- and intra-group risk of group-based microlending on the sustainable development of microfinance.

\section{Acknowledgements}

I thank to the Editor and the referee for their comments. I am grateful to Lutz Arnold for his supervising and useful discussion. I also want to thank Raphael Dimpfl and Jeniffer Ritter for their suggestions. Financial support from the University of Regensburg is gratefully acknowledged. All errors are naturally mine.

\section{References}

[1] Grammen Bank (2016) Issue No: 437. http://www.grameen.com

[2] Ghatak, M. and Guinnane, T. (1999) The Economics of Lending with Joint Liability: Theory and Practice. Journal of Development Economics, 60, 195-228. https://doi.org/10.1016/S0304-3878(99)00041-3

[3] Stiglitz, J.E. (1999) Peer Monitoring and Credit Markets. The World Bank Economic Review, 4, 351-366. https://doi.org/10.1093/wber/4.3.351

[4] Armendáriz de Agion, B. (1999) On the Design of a Credit Agreement with Peer Monitoring. Journal of Development Economics, 60, 79-104. https://doi.org/10.1016/S0304-3878(99)00037-1

[5] Kurosaki, T. and Khan, H.U. (2012) Vulnerability of Microfinance to Strategic Default and Covariate Shocks: Evidence from Pakistan. The Developing Economies, 50, 81-115. https://doi.org/10.1111/j.1746-1049.2012.00160.x

[6] Diamond, D.W. (1984) Financial Intermediation and Delegated Monitoring. Review of Economic Studies, 51, 393-414. https://doi.org/10.2307/2297430

[7] Laux, C. (2001) Limited-Liability and Incentive Contracting with Multiple Projects. RAND Journal of Economics, 32, 514-526. https://doi.org/10.2307/2696366

[8] Conning, J. (2005) Monitoring by Delegates or by Peers? Joint Liability Loans under Moral Hazard. Unpublished Research Paper 407, Hunter College, Department of Economics, Manhattan. 
[9] Baland, J.-M., Somanathan, R. and Wahhaj, Z. (2013) Repayment Incentives and the Distribution of Gains from Group Lending. Journal of Development Economics, 105, 131-139. https://doi.org/10.1016/j.jdeveco.2013.07.008

[10] Ahlin, C. (2015) The Role of Group Size in Group Lending. Journal of Development Economics, 115, 140-155. https://doi.org/10.1016/j.jdeveco.2015.03.001

[11] Besley, T. and Coate, S. (1995) Group Lending, Repayment Incentives and Social Collateral. Journal of Development Economics, 46, 1-18. https://doi.org/10.1016/0304-3878(94)00045-E

[12] Bhole, B. and Ogden, S. (2010) Group Lending and Individual Lending with Strategic Default. Journal of Development Economics, 91, 348-363. https://doi.org/10.1016/j.jdeveco.2009.06.004

[13] Rai, A. and Sjöström, T. (2010) Redesigning Microcredit. In: Vulkan, N., Roth, A.E. and Neeman, Z., Eds., The Handbook of Market Design, Published to Oxford Scholarship Online: January 2014, Chapter 9.

[14] Arnold, L., Reeder, J. and Steger, S. (2013) On the Viability of Group Len-ding when Microfinance Meets the Market. A Reconsideration of the Besley-Coate Model. Journal of Emerging Market Finance, 12, 59-106. https://doi.org/10.1177/0972652712473403

[15] Ahlin, C. (2009) Matching for Credit: Risk and Diversification in Thai Microcredit Groups. Unpublished Research Paper, Michigan State University, East Lansing.

Submit or recommend next manuscript to SCIRP and we will provide best service for you:

Accepting pre-submission inquiries through Email, Facebook, LinkedIn, Twitter, etc. A wide selection of journals (inclusive of 9 subjects, more than 200 journals)

Providing 24-hour high-quality service

User-friendly online submission system

Fair and swift peer-review system

Efficient typesetting and proofreading procedure

Display of the result of downloads and visits, as well as the number of cited articles

Maximum dissemination of your research work

Submit your manuscript at: http://papersubmission.scirp.org/

Or contact tel@scirp.org 